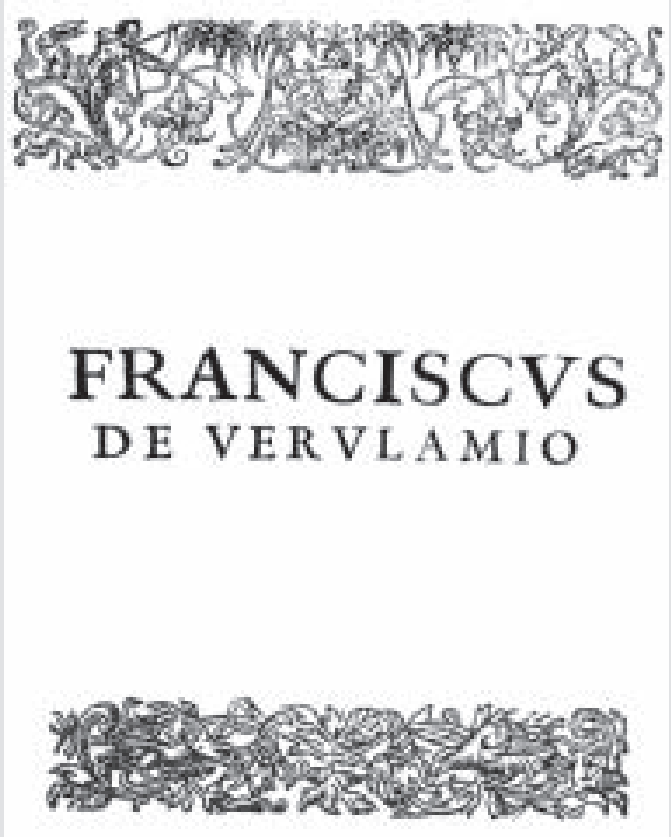

De fluxu et refluxu maris

Contemplatio de causis fluxus et refluxus maris, ab antiquis tentata et deinde omissa, junioribus repetita, et tamen varietate opinionum magis labefactata quam discussa, vulgo levi conjectura refertur ad Lunam, ob consensum nonnullum motus ejusdem cum motu Lunæ. Attamen diligentius perscrutanti vestigia quædam veritatis se ostendunt, quæ ad certiora deducere possint. Itaque ne confusius agatur, primo distinguendi sunt motus maris, qui licet satis inconsiderate multiplicentur a nonnullis, inveniuntur revera tantum quinque; quorum unus tanquam anomalus est, reliqui constantes. 

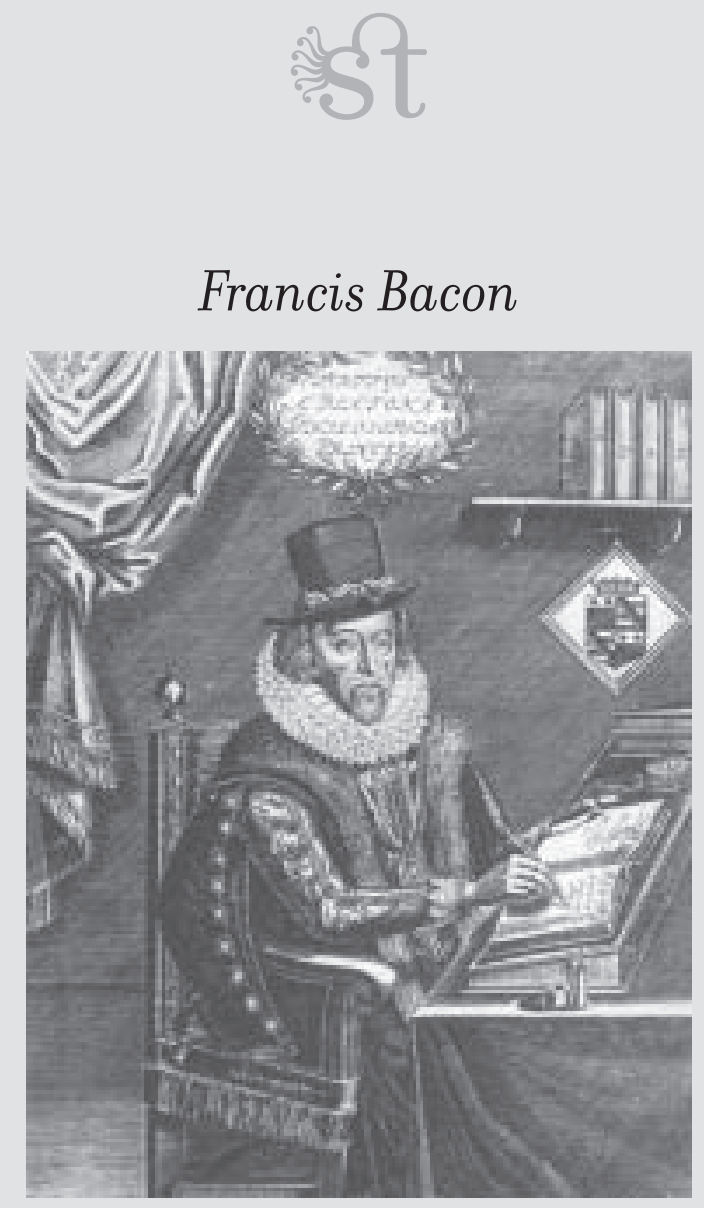

\section{Do fluxo e refluxo do mar ${ }^{1}$}

O exame das causas do fluxo e refluxo do mar, tentado pelos antigos e posteriormente deixado de lado, retomado pelos mais modernos e, contudo, mais enfraquecido que resolvido pela diversidade de opiniões, é vulgarmente, por conjectura ligeira, referido à Lua, devido a algum consenso desse movimento com o movimento da Lua. Mas, a quem investiga mais diligentemente mostram-se certos vestígios da verdade que poderiam levar a coisas mais certas. Assim, para que não haja confusão, devemos primeiramente distinguir os movimentos do mar, os quais, embora alguns multipliquem muito inconsideradamente, são realmente cinco movimentos, dos quais um é como se fosse irregular, e os demais são constantes. 
Primus ponatur motus ille vagus et varius (quos appellant) currentium. Secundus motus magnus oceani sexhorarius, per quem aquæ ad littora accedunt et recedunt alternatim bis in die, non exacte, sed cum differentia tali quæ periodum constituat menstruam. Tertius motus ipse menstruus, qui nil aliud est quam restitutio motus (ejus quem diximus) diurni ad eadem tempora. Quartus motus semimenstruus, per quem fluxus habent incrementa in noviluniis et pleniluniis, magis quam in dimidiis. Quintus motus semestris, per quem fluxus habent incrementa auctiora et insignia in æquinoctiis. Atque de secundo illo motu magno oceani sexhorario sive diurno, nobis in præsentia sermo est præcipue et ex intentione; de reliquis solummodo in transitu, et quatenus faciant ad hujusce motus explicationem. Primo igitur, quod ad motum currentium attinet, dubium non est quin pro eo ac aquæ vel ab angustiis premuntur, vel a liberis spatiis laxantur, vul in magis declivia festinant ac veluti effunduntur, vel in eminentiora incurrunt ac inscendunt, vel fundo labuntur æquabili, vel fundi sulcis et inæqualitatibus perturbantur, vel in alios currentes incidunt, atque cum illis se miscent et compatiuntur, vel etiam a ventis agitantur, præsertim anniversariis sive statariis, qui sub anni certas tempestates redeunt, aquas ex his et similibus causis impetus et gurgites suos variare tam consecutione ipsius motus atque latione, quam velocitate sive mensura motus, atque inde constituere eos quos vocant currentes. Itaque in maribus, tum profunditas fossæ sive canalis atque interpositæ voragines et rupes submarinæ, tum curvitates littorum, et terrarum prominentiæ, sinus, fauces, insulæ multis modw locatæ, et similia, plurima possunt, atque agunt prorsus aquas earumque meatus et gurgites in omnes partes, et versus orientem et versus occidentem, austrum versus similiter et septentriones, atque quaqua versum prout obices illi aut spatia libera et declivia sita sint et invicem configurentur. Segregetur igitur motus iste aquarum particularis, et quasi fortuitus, ne forte ille in inquisitione quam prosequimur obturbet. Neminem enim par est constituere et fundare abnegationem eornm, quæ mox dicentur de motibus oceani naturalibus et catholicis, opponendo motum istum currentium, veluti cum thesibus illis minime convenientem. Sunt enim currentes meræ compressiones aquarum, aut liberationes a compressione. Suntque, ut diximus, particulares et respectivi, prout locantur aquæ et terræ, aut etiam incumbunt venti. Atque hoc quod diximus eò magis memoria tenendum est, atque diligenter advertendum, quia motus ille universalis oceani, de quo nunc agitur, adeo mitis est et mollis ut a compulsionibus currentium 
Tome-se, como primeiro, aquele movimento inconstante e diferente (das chamadas) correntes. O segundo é o grande movimento do oceano de 6 horas, pelo qual as águas sobem e descem às margens alternadamente duas vezes ao dia, não de forma precisa, mas com diferença tal que constitui o período mensal. O terceiro é o próprio movimento mensal, que nada mais é que o restabelecimento do movimento diurno (do qual falamos) a idêntica situação anterior. Quarto, o movimento quinzenal, pelo qual os fluxos se incrementam nos novilúnios e plenilúnios, mais do que nos quartos. Quinto, o movimento semestral, no qual os fluxos possuem incrementos maiores e notáveis nos equinócios. Mas é acerca daquele segundo grande movimento do oceano de seis horas, ou o diurno, que no momento precipuamente interessa discutir; dos demais, somente de passagem e na medida em que contribuam para a explicação desse movimento.

Primeiramente, portanto, no que se refere ao movimento das correntes, não há dúvida de que, em conformidade com esse movimento, as águas ou são premidas por espaços estreitos, ou alargam-se nos espaços livres ou, sobretudo, nos declives, agitam-se e como que afundam, ou lançam-se e sobem nos lugares proeminentes, ou deslizam no fundo uniforme, ou perturbam-se pelos sulcos e irregularidades do fundo, ou chocam-se com outras correntes e às mesmas misturam-se e reúnem-se, ou ainda são agitadas pelos ventos, principalmente os anuais ou mesmo os constantes, que retornam em determinadas épocas do ano. Não há dúvida de que as águas, a partir dessas e de causas semelhantes, variam o ímpeto e suas agitações tanto pela conseqüência e resultado do próprio movimento, quanto pela velocidade ou medida do movimento, e daí [não há dúvida] de elas constituírem estas que se chamam correntes. E assim, nos mares, tanto a profundidade da fossa ou do canal como também abismos interpostos e rochedos submarinos, assim como as sinuosidades dos litorais e os promontórios das terras, os golfos, os desfiladeiros, as ilhas dispostas de várias maneiras e coisas similares, podem muito e impelem para frente as águas, os movimentos e as agitações delas para todas as direções, para oriente e ocidente, para austral e igualmente para setentrião, e para todos os lados, de acordo com a localização dos obstáculos ou dos espaços livres e declives e igualmente de sua configuração. Deixe-se de lado, portanto, este movimento particular e quase casual das águas, para que ele não venha a atrapalhar a investigação que perseguimos. De fato, convém que ninguém constitua e justifique a recusa daquilo que imediatamente se dirá acerca dos movimentos naturais e universais do oceano, opondo esse movimento das correntes, como se pouco conviesse com essas teses. De fato, as correntes são simples compressões das águas, ou liberações oriundas da compressão; são, como dissemos, particulares e relativas, de acordo com a localização das águas e das terras e ainda da ação dos ventos. E o que dissemos deve ser retido na memória e diligentemente observado porque aquele movimento universal do oceano, do qual agora se trata, é tão calmo e suave que, sob os impulsos das correntes submete-se 
omnino dometur, et in ordinem redigatur, cedatque et ad eorum violentiam agatur et regatur. Id autem ita se habere ex eo perspicuum est vel maxime, quod motus simplex fluxus et refluxus maris in pelagi medio, præsertim per maria lata et exporrecta non sentiatur, sed ad littora tantum. Itaque nihil mirum si sub currentibus (utpote viribus inferior) lateat et quasi destruatur, nisi quod ille ipse motus, ubi currentes secundi fuerint, eorum impetum nonnihil juvet atque incitet, contra ubi adversi, modicum frænet. Misso igitur motu currentium pergendum est ad motus illos quatuor constantes, sexhorarium, menstruum, semimenstruum, et semestrem; quorum solus sexhorarius videtur fluxus maris agere et ciere, menstruus vero videtur tantummodo motum illum determinare et restituere, semimenstruus autem et semestris eundem augere et intendere. Etenim fluxus et refluxus aquarum, qui littora maris ad certa spatia inundat et destituit, et horis [variis] variat et vi ac copia aquarum, unde reliqui illi tres motus se dant conspiciendos. Itaque de illo ipso motu fluxus et refluxus sigillatim ac proprie (ut instituimus) videndum. Atque primo illud dari prorsus necesse est, motum hunc, de quo inquirimus, unum ex duobus istis esse, vel motum sublationis et demissionis aquarum, vel motum progressus. Motum autem sublationis et demissionis talem esse intelligimus, qualis invenitur in aqua bullienti, quæ in caldario attollitur et rursum residet. At motum progressus talem, qualis invenitur in aqua vecta in pelvi, quæ unum latus deserit, cum ad latus oppositum advolvitur. Quod vero motus iste neutiquam sit primi generis, occurrit illud inprimis, quod in diversis mundi partibus variant æstus secundum tempora; ut fiant in aliquibus locis fluxus et augmenta aquarum, cum alibi sint ad eas horas refluxus et decrementa. Debuerant autem aquæ, si illæ non progrederentur de loco in locum, sed ex profundo ebullirent, ubique simul se attollere, atque rursus simul se recipere. Videmus enim duos illos alios motus, semestrem et semimenstruum, per universum orbem Terrarum simul perfungi atque operari. Fluxus enim sub aequinoctiis ubique augentur; non in aliis partibus sub aequinoctiis, in aliis sub tropicis; atque similis est ratio motus semimenstrui. Ubique enim terrarum invalescunt aquae in noviluniis, nullibi in dimidiis. Itaque videntur revera aquæ in duobus illis motibus plane attolli et demitti, et veluti pati apogæum et perigæum, quemadmodum cœlestia. Atque in fluxu et refluxu maris, de quo sermo est, contra fit: quod motus in progressu certissimum signum est. Praeterea si fluxus aquarum ponatur esse sublatio, attenden- 
totalmente e reconduz-se à ordem, cedendo, é levado pela violência dos impulsos e dominado. Mas isso é notável principalmente a partir do seguinte: que o movimento simples do fluxo e refluxo no meio do mar, sobretudo nos mares abertos e extensos, não se percebe, mas somente no litoral. E assim, em nada surpreende se sob as correntes (na medida em que é inferior na força) se esconda e quase se destrua, exceto se esse mesmo movimento, onde ocorressem correntes secundárias, auxilie ou incite algum ímpeto do movimento; contrariamente, onde são adversos, refreia moderadamente.

Portanto, suprimido o movimento das correntes, deve-se dirigir [a investigação] para os outros quatro movimentos constantes: o das 6 horas, o mensal, o quinzenal e o semestral, dos quais somente no de 6 horas se vê o fluxo do mar agir e mover-se; mas o mensal parece só determinar e restituir aquele das 6 horas e, por sua vez, o quinzenal e o semestral aumentá-lo e intensificá-lo. Com efeito, o fluxo e refluxo das águas inunda e esvazia os litorais em lugares determinados e varia segundo a variação das horas e a força e a quantidade das águas, daí que os três movimentos restantes se apresentem como visíveis.

E assim, a respeito do movimento próprio do fluxo e refluxo, deve-se considerálo (como estabelecemos) propriamente e em si mesmo. E primeiramente é necessário que se conceda imediatamente o seguinte: o movimento do qual indagamos é um destes dois: ou o movimento de aumento e de diminuição das águas, ou o movimento de progressão [das águas]. Ora, o movimento de aumento e de diminuição julgamos ser tal qual se encontra na água fervente, que se eleva nas caldeiras e em seguida aquieta-se. E o movimento de progressão é tal qual se encontra na água transportada em uma bacia, da qual a que deixa um lado dirije-se ao lado oposto. Mas este movimento de modo algum é do primeiro gênero, principalmente porque acontece que, em diferentes partes do mundo, as marés variam de acordo com as estações, de modo que ocorrem em alguns lugares o fluxo e o aumento das águas, embora em outro lugar nessas horas haja refluxo e diminuição. Por outro lado, se as águas não progredissem de local em local mas fervessem da profundeza, deveriam levantar-se e recolher-se de todo lugar ao mesmo tempo.

Observamos ainda esses dois outros movimentos, semestral e quinzenal, realizarem-se e fazerem-se, ao mesmo tempo, pela totalidade do orbe terrestre. Os fluxos, com efeito, aumentam em todo lugar nos equinócios e não em algumas partes nos equinócios, outras nos trópicos, mas similar é a razão do movimento quinzenal. Portanto, em todas as partes da Terra, as águas se fortalecem na Lua nova e, em nenhuma parte, na meia Lua. E assim realmente as águas são vistas naqueles dois movimentos totalmente elevar-se e baixar, e como que sofrer um apogeu e um perigeu do mesmo modo que os corpos celestes. Mas no fluxo e refluxo do mar, do qual este texto trata, ocorre o contrário: o que é um sinal certíssimo do movimento em progressão. Além disso, se se 
dum paulo diligentius quomodo ista sublatio fieri possit. Aut enim fiet tumor ab aucto quanto aquarum, aut ab extensione sive rarefactione aquarum in eodem quanto, aut per sublationem simplicem in eodem quanto atque eodem corpore. Atque tertium illud prorsus abjiciendum. Si enim aqua, qualis est, attollatur, ex hoc relinquatur necessario inane inter terram atque ima aquæ, cum non sit corpus quod succedat. Quod si sit nova moles aquæ, necesse est eam emanare atque scaturire è terra. Sin vero sit extensio tantum, id fiet vel per solutionem in magis rarum, vel appetitum appropinquandi ad aliud corpus, quod aquas veluti evocet et attrahat et in sublimius tollat. Atque certe ista aquarum sive ebullitio, sive rarefactio, sive conspiratio cum alio quopiam corpore ex superioribus, non incredibilis videri possit in mediocri quantitate, atque adhibito etiam bono temporis spatio, in quo hujusmodi tumores sive augmenta se colligere et cumulare possint. Itaque excessus ille aquarum, qui inter æstum ordinarium, atque æstum illum largiorem semimenstruum aut etiam illum alterum profusissimum semestrem notari possit, cum nec mole excessus inter fluxum et refluxum æquiparetur atque habeat etiam bene magnum intervallum temporis ad incrementa illa sensim facienda, nihil habeat alienum a ratione. Ut vero tanta erumpat moles aquarum, quæ excessum illum, qui invenitur inter ipsum fluxum et refluxum, salvet; atque hoc fiat tanta celeritate, videlicet bis in die, ac si terra secundum vanitatem illam Apollonii respiraret, atque aquas per singulas sex boras efflaret, ac deinde absorberet; incommodum maximum. Neque moveatur quispiam levi experimento, quod putei nonnulli in aliquibus locis memorentur consensum habere cum fluxu et refluxu maris; unde suspicari quis possit, aquas in cavis terræ conclusas similiter ebullire; in quo casu tumor ille ad motum progressivum aquarum referri commode non possit. Facilis enim est responsio, posse fluxum maris accessione sua multa loca cava ac laxa terræ obturare atque opplere, atque aquas subterraneas vertere, etiam aërem conclusum reverberare, qui serie continuata hujusmodi puteorum aquas trudendo attollere possit. Itaque hoc in omnibus puteis minime fit, nec in multis adeo, quod fieri debuit si universa massa aquarum naturam haberet ebullientem per vices, et cum æstu maris consensionem. Sed contra raro admodum fit, ut instar miraculi fere habeatur; quia scilicet hujusmodi laxamenta et spiracula, quæ a puteis ad mare pertingunt, absque obturatione aut impedimento raro admodum inveniantur. Neque abs re est memorare quod referunt nonnulli, in fodinis profundis, non procul a mari sitis, aërem incrassari et suffocationem minari ad tempora fluxus maris; ex quo manifestum videri possit non 
considerasse que o fluxo das águas é a elevação, faltaria atentar com mais cuidado como isso pode acontecer. Pois produziria o inchaço das águas, ou pelo aumento tão grande das águas, ou pela extensão, ou seja, pela rarefação das águas nessa mesma quantidade, ou pela elevação simples nessa mesma quantidade e no mesmo corpo.

E esse terceiro pode ser imediatamente posto de lado. Se de fato a água, tal qual é, se elevasse, deixaria necessariamente um vazio entre a terra e o mais profundo da água, visto que não existe corpo que entre por baixo. Quanto a isso, se existesse uma nova quantidade de água, seria necessário que a mesma se originasse e brotasse da terra. Mas se, ao contrário, houvesse tamanha extensão, seria, seja por solução em algo menos denso, seja pelo apetite de aproximar-se de outro corpo, que às águas como que evocasse, atraísse e alçasse mais para cima. E certamente esta ebulição ou rarefação ou conspiração das águas com outro corpo de algum dos lugares superiores não poderia parecer indigna de crédito em pequena quantidade e, mesmo acrescendo um bom intervalo de tempo, no qual desse modo os inchaços ou aumentos poderiam reunir-se e acumular-se. E assim aquele excesso de água, que poderia ser notado entre a maré ordinária e aquela maior quinzenal ou também aquela outra mais ampla semestral, nada tem de alheio à razão, pois nem o tamanho do excesso entre o fluxo e o refluxo se equipara, e tem um grande intervalo de tempo para que aqueles aumentos se façam pouco a pouco. É, no entanto, um grande inconveniente que irrompa tanta quantidade de água que conserve aquele excesso que se encontra entre o próprio fluxo e o refluxo e que isso aconteça com tanta velocidade duas vezes ao dia, como se a terra, segundo a famosa tolice de Apolônio, respirasse a cada seis horas, expirando as águas e depois inspirando-as. E que ninguém se deixe levar pelo frívolo experimento de alguém que diz que, em certos lugares de alguma cavidade, há consenso com o fluxo e o refluxo do mar; donde alguém poderia suspeitar que as águas retidas nas profundezas da Terra fervam similarmente; nesse caso, aquele inchaço não poderia ser facilmente referido ao movimento progressivo das águas. Pois a resposta é fácil: o fluxo do mar pode, por sua aproximação, obstruir e preencher muitos lugares fundos e largos da terra frouxa, e verter as águas subterrâneas e também reverberar o ar retido, o qual, numa série que continua desse modo, poderia elevar as águas das fossas, agitando-as. Assim, absolutamente não ocorre em todas as fossas, tampouco aliás em muitas; o que deveria acontecer, se a massa total das águas tivesse por vezes uma natureza ebuliente em conformidade com a agitação do mar. Mas, ao contrário, raramente ocorre a ponto de quase ser tido como milagre, já que certamente é raro que se encontre tais alargamentos e aberturas que se estendem das fossas para o mar sem obstrução ou sem impedimento. Nem é fora de propósito lembrar o que alguns referem: em minas profundas, localizadas não distantes do mar, o ar torna-se denso e ameaça de sufocação nos tempos do 
aquas ebullire (nullæ cum cernuntur), sed aërem retroverti. At certe aliud urget experimentum non contemnendum, sed magni ponderis, cui responsio omnino debetur; hoc est, quod diligenter observatum sit, idque non fortuito notatum, sed de industria inquisitum atque repertum, aquas ad littora adversa Europæ et Floridæ iisdem horis ab utroque littore refluere, neque deserere littus Europæ cum advolvantur ad littora Floridæ, more aquæ (ut supra diximus) agitatæ in pelvi, sed plane simul ad utrumque littus attolli et demitti. Verum hujus objectionis solutio perspicue apparebit in iis quae mox dicentur de cursu et progressu oceani. Summa autem rei talis est, quod aquæ a mari Indico profectæ, et ab objectu terrarum veteris et novi orbis impeditæ, truduntur per mare Atlanticum ab Austro in Boream; ut non mirum sit eas ad utrumque littus simul ex æquo appellere, ut aquæ solent, quæ contruduntur a mari in ostia et canales fluminum, in quibus evidentissimum est motum maris esse progressivum quatenus ad flumina, et tamen littora adversa simul inundare. Verum id pro more nostro ingenue fatemur, idque homines attendere et meminisse volumus, si per experientiam inveniatur, fluxus maris iisdem temporibus ad littora Peruviæ atque Chinæ affluere, quibus fluunt ad littora præfata Europæ et Floridæ, opinionem hanc nostram, quod fluxus et reflux us maris sit motus progressivus, abjudicandam esse. Si enim per littora adversa tam maris Australis quam maris Atlantici fiat fluxus ad eadem tempora, non relinquuntur in universo alia littora per quæ refluxus ad eadem illa tempora satisfaciat. Verum de hoc judicio faciendo per experientiam (cui causam submisimus) loquimur tanquam securi. Existimamus enim plane, si summa hujus rei per universum terrarum orbem nobis cognita foret, satis æquis conditionibus istud fœdus transigi, nempe ut ad horam aliquam certam fiat refluxus in aliquibus partibus orbis, quantum fiat fluxus in aliis. Quamobrem ex iis, quæ diximus, statuatur tandem, motus iste fluxus et refluxus esse progressivus.

Sequitur jam inquisitio ex qua causa, et per quem consensum rerum oriatur atque exhibeatur iste motus fluxus et refluxus. Omnes enim majores motus (si sunt iidem regulares et constantes) solitarii aut (ut astronomorum vocabulo utamur) ferini non sunt, sed habent in rerum natura cum quibus consentiant. Itaque motus illi, tam semimenstruus incrementi quam menstruus restitutionis, convenire videntur cum motu Lunæ; semimenstruus vero ille sive æquinoctialis cum motu Solis; etiam sublationes et demissiones aquarum cum apogæis et perigæis cœlestium. Neque tamen continuo 
fluxo do mar; a partir do que poderia parecer evidente que as águas não fervem (já que nenhuma se percebe assim), mas que o ar faz o contrário. Mas certamente urge que outro experimento não seja desprezado, pois de maior peso, ao qual se deve somente a resposta; e é - o que se deve diligentemente observar, e isso deve ser notado não fortuitamente mas zelosamente investigado e encontrado - que as águas das costas opostas da Europa e da Flórida, nas mesmas horas de ambos os litorais, refluem e nem deixam o litoral da Europa quando se voltam para o litoral da Flórida - ao modo das águas (como dissemos acima) agitadas na bacia - mas uniformemente levantam-se e abaixam-se em ambos os litorais. Mas a solução dessa objeção aparecerá claramente no que for dito a seguir sobre o curso e a progressão do oceano. O cerne da questão é que as águas provenientes do mar Índico, impedidas pelos obstáculos das terras do Velho e do Novo Mundo, empurram pelo mar Atlântico de austral para boreal, ${ }^{2}$ de modo que não é admirável que elas se aproximem de ambos os litorais ao mesmo tempo e de igual maneira, como usualmente faz o mar, empurrando as águas com força nas embocaduras e nos canais dos rios, nos quais é muito evidente que o movimento do mar é progressivo com relação aos rios, apesar dos litorais opostos inundarem-se simultaneamente. Mas isso, segundo nosso costume, afirmamos sinceramente e queremos que os homens atentem e lembrem-se do seguinte: se se constatar por experiência que o fluxo do mar aflui nos litorais do Peru e nas costas da China nos mesmos tempos pelos quais fluem para os litorais anteriormente ditos da Europa e da Flórida, essa nossa opinião de que o fluxo e refluxo do mar seja um movimento progressivo deve ser abandonada. Se, de fato, pelos litorais opostos tanto do mar Austral quanto do Atlântico ocorrer o fluxo ao mesmo tempo, não restarão em absoluto outros litorais pelos quais o refluxo se faria naquele mesmo tempo. Mas sobre esse juízo que deve ser feito por experiência (à qual submetemos o caso), falamos como se estivéssemos seguros, pois estimamos claramente que, se o cerne desse assunto nos fosse conhecido para todo o orbe terrestre, este tratado seria suficientemente levado a termo por eqüânimes condições, de tal forma que a uma dada hora determinada aconteça o refluxo em algumas partes do mundo na mesma proporção que o fluxo em outras partes. Pelo que dissemos, fica finalmente estabelecido que esse movimento do fluxo e refluxo é progressivo.

Segue-se agora a investigação: a partir de que causa, e por qual consenso das coisas se origina e se mostra esse movimento do fluxo e refluxo? Pois todos os maiores movimentos (se os mesmos são regulares e constantes), não são isolados ou (usando o termo dos astrônomos) ferinos, ${ }^{3}$ mas estão em consenso com a natureza das coisas. E assim, aqueles movimentos, tanto os quinzenais de aumento, como os mensais de restituição parecem convir com o movimento da Lua. Mas aquele quinzenal ou equinocial parece convir com o movimento do Sol. Também os aumentos e diminuições das águas parecem 
sequetur (idque homines advertere volumus), quæ periodis et curriculo temporis aut etiam modo lationis conveniunt, ea natura esse subordinata, atque alterum alteri pro causa esse. Nam non eo usque progredimur, ut affirmemus motus Lunæ aut Solis pro causis poni motuum inferiorum, qui ad illos sunt analogi; aut solem et lunam (ut vulgo loquuntur) dominium habere super illos motus maris (licet hujusmodi cogitationes facile mentibus hominum illabantur ob venerationem cœlestium); sed et in illo ipso motu semimenstruo (si recte advertatur) mirum et novum prorsus fuerit obsequii genus, ut æstus sub noviluniis et pleniluniis eadem patiantur, cum luna patiatur contraria; et multa alia adduci possint quæ hujusmodi dominationum phantasias destruant, et eo potius rem deducant, ut ex materiæ passionibus catholicis et primis rerum coagmentationibus consensus illi oriantur, non quasi alterum ab altero regatur, sed quod utrumque ab iisdem originibus et concausis emanet. Veruntamen (utcunque) manet illud quod diximus, Naturam consensu gaudere, nec fere aliquid monodicum aut solitarium admittere. Itaque videndum de motu fluxus et refluxus maris sexhorario, cum quibus aliis motibus ille convenire aut consentire reperiatur. Atque inquirendum primo de Luna, quomodo iste motus cum Luna rationes aut Naturam misceat. Id vero fieri omnino non videmus, præterquam in restitutione menstrua: nullo modo enim congruit curriculum sexhorarium (id quod nunc inquiritur) cum curriculo menstruo; neque rursus fluxus maris passiones Lunæ quascumque sequi deprehenduntur. Sive enim Luna sit aucta lumine, sive diminuta, sive illa sit sub terra, sive super terram, sive illa elevetur super horizontem altius aut depressius, sive illa ponatur in meridiano, aut alibi, in nulla prorsus harum consentiunt fluxus atque refluxus.

Itaque missa Luna, de aliis consensibus inquiramus. Atque ex omnibus motibus cœlestibus constat, motum diurnum maxime curtum esse, et minimo temporis intervallo (spatio videlicet 24, horarum) confici. Itaque consentaneum est, motum istum, de quo inquirimus (qui adhuc tribus parti bus diurno brevior est) proxime ad eum motum referri qui est ex cœlestibus brevissimus; sed hoc rem minus premit. Illud vero longe magis nos movet, quod ita sit iste motus dispertitus, ut ad diurni motus rationes respondeat; ut licet motus aquarum sit motu diurno quasi innumeris partibus tardior, tamen sit commensurabilis. Etenim spatium sexhorarium est diurni motus quadrans, quod spatium (ut diximus) in motu isto maris invenitur cum ea differentia, quæ coin- 
convir com os apogeus e perigeus dos corpos celestes. Nem contudo seguir-se-á imediatamente (e quanto a isso queremos advertir) que essas que convêm nos períodos e no curso do tempo, ou ainda no modo de movimento, foram subordinadas pela natureza e que uma tenha a outra como causa. Com efeito, não avançamos até o ponto de afirmar que os movimentos da Lua ou do Sol são postos como causa dos movimentos inferiores que lhe são análogos ou que o Sol e a Lua (como vulgarmente se diz) têm domínio sobre aqueles movimentos do mar (embora cogitações desse tipo facilmente penetrem nas mentes dos homens em virtude da veneração dos corpos celestes); mas também naquele próprio movimento quinzenal (se corretamente observado), ocorreria imediatamente um gênero de complacência admirável e novo, de modo que o movimento das águas sob os novilúnios e os plenilúnios padecem as mesmas coisas, embora a Lua padeça coisas contrárias, e muitas outras poderiam ser aduzidas que destruiriam tais fantasias de dominação e antes conduziriam à conclusão de que aqueles consensos surgiriam das paixões universais da matéria e das primeiras conjunções das coisas, não como se um fosse regido pelo outro, mas porque cada um emanaria das mesmas origens e de causas comuns. Contudo, permanece (de qualquer modo) o que dissemos, a natureza se compraz com o consenso, quase nunca admite alguma coisa única ou solitária. E, desse modo, deve-se observar a respeito do movimento de 6 horas do fluxo e refluxo do mar com quais outros movimentos se constata que ele convém ou consente. E assim, deve-se investigar primeiramente a respeito da Lua, de que modo esse movimento mescla razões e natureza com a Lua. Mas isso absolutamente não vemos ocorrer a não ser na restituição mensal, pois de nenhum modo coincide o curso de 6 horas (o que agora se investiga) com o curso mensal; nem, pelo contrário, constatase que os fluxos do mar acompanhem as paixões da Lua, pois seja a Lua crescente ou minguante, ou esteja abaixo da Terra ou acima da Terra, ou esteja além do horizonte mais alta ou mais baixa ou posta no meridiano ou em outro lugar, com nenhuma dessas situações o fluxo e refluxo está em consenso.

E assim, deixando de lado a Lua, investiguemos acerca dos outros consensos. É evidente que o movimento diurno é o mais breve de todos os movimentos celestes e executado no menor intervalo de tempo (isto é, no intervalo de 24, horas). E assim, tem-se como conseqüência que esse movimento do qual falamos (que é mais breve do que o diurno por três quartos) refere-se aproximadamente a este movimento que é o mais breve entre os movimentos celestes; mas esta questão não é tão relevante. Mas aquilo que de longe nos interessa mais é que de este movimento seja distribuído de tal modo que responda às razões do movimento diurno; de modo que, embora o movimento das águas seja mais lento que o movimento diurno em partes quase inumeráveis, no entanto é comensurável. Com efeito, o intervalo de 6 horas é a quarta parte do movimento diurno, e esse intervalo (como dissemos) encontra-se nesse movimento 
cidat in mensuram motus Lunæ. Itaque hoc nobis penitus insedit, ac fere instar oraculi est, motum istum ex eodem genere esse cum motu diurno. Hoc igitur usi fundamento pergemus inquirere reliqua; atque rem omnem triplici inquisitione absolvi posse statuimus. Quarum prima est, an motus ille diurnus terminis coeli contineatur, aut delabatur, et se insinuet ad inferiora? Secunda est, an maria regulariter ferantur ab oriente in occidentem, quemadmodum et cœlum? Tertia, unde et quomodo fiat reciprocatio illa sexhoraria æstuum, quæ incidit in quadrantem motus diurni, cum differentia incidente in rationes motus Lunæ? Itaque quod ad primam inquisitionem attinet, arbitramur motum rotationis sive conversionis ab oriente in occidentem esse motum non proprie cœelestem, sed plane cosmicum, atque motum in fluoribus magnis primarium, qui usque a summo cœlo ad imas aquas inveniatur, inclinatione eadem, incitatione autem (id est velocitate et tarditate) longe diversa; ita tamen ut ordine minime perturbato minuatur celeritate, quo propius corpora accedunt ad globum terræ. Videtur autem primo probabile argumentum sumi posse, quod motus iste non terminetur cum colo, quia per tantam cœli profunditatem, quanta interjicitur inter cœlum stellatum et Lunam (quod spatium multo amplius est, quam a Luna ad terram), valeat atque vigeat iste motus, cum debitis decrements suis; ut verisimile non sit Naturam istiusmodi consensum, per tanta spatia continuatum et gradatim se remittentem, subito deponere. Quod autem res ita se habeat in cœlestibus evincitur ex duobus, quæ aliter sequentur, incommodis. Cum enim manifestum sit ad sensum, planetas diurnum motum peragere, nisi ponatur motus iste tanquam naturalis, ac proprius in planetis omnibus, confugiendum necessario est vel ad raptum primi mobilis, quod naturæ prorsus adversatur, aut ad rotationem terræ, quod etiam satis licenter excogitatum est, quoad rationes physicas. Itaque in cœlo ita se res habet. Postquam autem a cœlo discessum est, cernitur porro iste motus evidentissime in cometis humilioribus, qui, cum inferiores orbe Lunæ sint, tamen ab oriente in occidentem evidenter rotant. Licet enim habeant motus suos solitarios et irregulares, tamen in illis ipsis conficiendis interim communicant cum motu ætheris et ad eandem conversionem feruntur. Tropicis vero non continentur fere, nec habent regulares spiras, sed excurrunt quandoque versus polos, sed nihilominus in consecutione ab oriente in occidentem rotant. Atque hujusmodi motus iste licet magna acceperit decrementa (cum quo propius descendatur versus terram, eo et minoribus circulis conversio fiat, et nihilominus tardius) validus tamen utique manet, ut magna spatia 
do mar com essa diferença que coincide com a medida do movimento da Lua. E assim enraizou-se profundamente em nós, quase como um oráculo, que esse movimento é do mesmo gênero que o movimento diurno.

Portanto, utilizando isso como fundamento, continuemos a investigar o restante; e estabelecemos que toda a dificuldade pode ser resolvida por uma tríplice investigação. A primeira é: esse movimento diurno ficaria contido no limite do céu ou desceria e penetraria nas regiões inferiores? A segunda é: os mares seriam regularmente transportados de oriente para ocidente do mesmo modo que o céu? A terceira: de onde e de que modo ocorreria a reciprocação de 6 horas das marés, que coincide com a quarta parte do movimento diurno, coincidindo a diferença com as razões do movimento lunar?

Assim, no que se refere à primeira investigação, julgamos que o movimento de rotação ou de conversão de oriente para ocidente não é propriamente um movimento celeste, mas claramente cósmico e, além disso, o movimento primário em grandes correntes, que é descoberto desde o alto céu até as águas profundas, com a mesma inclinação, mas com a impetuosidade (ou seja, com a velocidade e o retardamento) muito diferente, de tal modo que, sendo a ordem minimamente perturbada, [o movimento] é diminuído pela rapidez à medida que os corpos se aproximam do globo terrestre. Parece, por outro lado, que se pode tomar primeiramente como argumento convincente que esse movimento não se limitaria ao céu, porque ele valeria e vigiria, com suas devidas diminuições, por tanta extensão do céu quanta se interpõe entre o céu estelar e a Lua (extensão que é muito mais ampla do que a da Lua até a Terra), de modo que não é verossímil que a natureza deixe subitamente de lado um tal consenso, que continua por tanta extensão e que se repõe gradativamente. Mas que assim aconteça nos céus, mostra-se a partir de duas dificuldades, que se seguiriam de outro modo. Pois, visto que é evidente aos sentidos que os planetas perfazem o movimento diurno, exceto se se coloca esse movimento como natural e próprio em todos os planetas, devese recorrer necessariamente ou ao arrastamento 4 do primeiro móvel, o que é completamente contrário à natureza, ou à rotação da Terra, o que também é imaginado muito arbitrariamente quanto às razões físicas. Portanto, é assim nos céus. Porém, depois que desce do céu, esse movimento é, além disso, discernido evidentissimamente nos cometas pouco elevados que, embora sejam inferiores ao orbe lunar, no entanto, rodam evidentemente de oriente para ocidente, pois, embora tenham seus movimentos isolados e irregulares, no entanto, ao executá-los, compartilham nesse momento o movimento do éter e são levados para a mesma conversão; quase não são contidos pelos trópicos, nem têm espirais regulares, mas avançam de quando em quando em direção aos pólos, embora não menos rodem na consecução de oriente para ocidente. E embora este movimento obtenha grandes diminuições (visto que quanto mais desce em direção à Terra, por menores círculos será a conversão e mais lentamente) permanece de 
brevi tempore vincere queat. Circumvolvuntur enim hujusmodi cometæ circa universum ambitum et terræ et aëris inferioris spatio 24, horarum, cum horæ unius aut alterius excessu. At postquam ad eas regiones descensu continuato perventum sit, in quas terra agit non solum communicatione Naturæ et virtutis suæ (quæ motum circularem reprimit et sedat), sed etiam immissione materiali particularum substantiæ suæ per vapores et halitus crassos, iste motus immensum hebescit, et fere corruit, sed non propterea prorsus exinanitur aut cessat, sed manet languidus et tamquam latens. Etenim jam in confesso esse cœpit, navigantibus intra Tropicos, ubi libero æquore motus aëris percipitur optime, et aër ipse (veluti et cœlum) majoribus circulis, ideoque velocius rotat, spirare auram perpetuam et jugem ab oriente in occidentem; adeo ut qui Zephyro uti volunt, eum extra tropicos sæpius quærant et procurent. Itaque non exstinguitur iste motus etiam in aëre infimo, sed piger jam devenit et obscurus, ut extra Tropicos vix sentiatur. Et tamen etiam extra Tropicos in nostra Europa in mari, cœlo sereno et tranquillo, observatur aura quædam solisequa, quæ ex eodem genere est; etiam suspicari licet, quod hic in Europa experimur, ubi flatus Euri acris est, et desiccans, cum contra Zephyri sit genialis et humectans, non solum ex hoc pendere, quod ille a continente, iste ab oceano apud nos spiret; sed etiam ex eo, quod Euri flatus, cum sit in eadem consequentia cum motu aëris proprio, eum motum incitet et irritet, ac propterea aërem dissipet et rarefaciat; Zephyri vero flatus, qui in contraria consequentia sit cum motu aëris, aërem in se vertat, et propterea inspisset. Neque illud contemnendum, quod vulgari observatione recipitur, nubes, quæ feruntur in sublimi plerumque movere ab oriente in occidentem, cum venti circa terram ad eadem tempora flant in contrarium. Quod si hoc non semper faciunt, id in causa esse, quod sint quandoque venti contrarii, alii in alto, alii in imo; illi autem in alto spirantes (si adversi fuerint) motum istum verum aëris disturbent. Quod ergo coeli terminis non contineatur iste motus, satis patet.

Sequitur ordine secunda inquisitio; An aquæ ferantur regulariter et naturaliter ab oriente in occidentem? Cum vero aquas dicimus, intelligimus aquas coacervatas, sive massas aquarum, quæ scilicet tantæ sunt portiones Naturæ, ut consensum habere possint cum fabrica et structura universi. Atque arbitramur plane, eundem motum massæ aquarum competere atque inesse, sed tardiorem esse quam in aëre, licet ob crassitudinem corporis sit magis visibilis et apparens. Itaque ex multis, quæ ad hoc adduci possent, tribus in præsens contenti erimus experiments, sed iisdem amplis et insignibus, quæ rem ita esse demonstrant. Primum est, quod manifestus reperiatur motus 
todo modo vigoroso, de modo que possa vencer grandes espaços em breve tempo. Pois tais cometas circunvolucionam em torno de toda órbita da Terra e do ar inferior no intervalo de 24, horas, com uma diferença de uma ou duas horas. Por outro lado, depois que chegasse a essas regiões numa descida contínua, para as quais a Terra conduz não somente por comunicação de sua natureza e virtude (a qual reprime e freia o movimento circular), mas também por emissão material das partículas de sua substância nas exalações e vapores densos, este movimento enfraquece enormemente e quase se destrói, mas nem por isso se esgota totalmente ou acaba, mas permanece lânguido e como que latente. Começa a ser reconhecido pelos que navegam nos trópicos que, em mar aberto, aonde o movimento do ar é percebido muito bem, e o próprio ar (como o céu) roda por círculos maiores e, por isso, mais velozmente, sopra uma aura perpétua e perene de oriente para ocidente, de tal modo que aqueles que querem usar o Zéfiro, freqüentemente o procurem e busquem fora dos trópicos. E assim, esse movimento também não se extingue no ar inferior, mas se torna vagaroso e obscuro, de modo que dificilmente é percebido fora dos trópicos. E todavia também além dos trópicos, em nossa Europa, com o céu sereno e tranqüilo, observa-se no mar uma certa aura que é do mesmo gênero; e ainda pode-se suspeitar que aquilo que experimentamos aqui na Europa, onde o sopro do Euro é violento e seco, embora, ao contrário, o do Zéfiro $^{5}$ seja próspero e úmido, não só depende de que aquele sopre do continente e este do oceano, mas também de que o sopro do Euro, embora esteja na mesma direção do movimento próprio do ar, incite e irrite esse movimento [do ar] e, por causa disso, dissipe e rarefaça o ar. Mas o sopro do Zéfiro, que está em direção oposta ao movimento do ar, dirige o ar para si e, por essa razão, inspira. Nem se deve desprezar aquilo que recolhido pela observação comum, que as nuvens que se movem no alto, movem-se freqüentemente de oriente para ocidente, embora os ventos em torno da Terra soprem, ao mesmo tempo, em sentido oposto. Que os ventos nem sempre fazem isso, a causa é que às vezes são contrários, alguns altos, outros baixos; aqueles que sopram no alto (se fossem opostos) perturbariam o verdadeiro movimento do ar. É suficientemente evidente, portanto, que este movimento não estaria contido nos limites do céu.

Segue-se na ordem a segunda investigação: as águas seriam levadas regular e naturalmente de oriente para ocidente? Quando dizemos “águas”, entendemos águas acumuladas, ou seja, massas de águas, que evidentemente são tantas partes da natureza, quantas podem estar em consenso com a arquitetura e estrutura do universo. E julgamos claramente que esse mesmo movimento compete à massa das águas e nela está contido, mas é mais lento que o movimento no ar, embora, devido à densidade do corpo, seja mais visível e aparente. E assim, das muitas coisas que possam ser aduzidas, contentamo-nos por ora com três experimentos, igualmente amplos e relevantes, que demonstram que a assim ocorre. O primeiro é que o movimento e o fluxo das águas 
et fluxus aquarum ab oceano Indico usque in oceanum Atlanticum, isque incitatior et robustior versus fretum Magellanicum, ubi exitus datur versus occidentem; magnum itidem ex adversa parte orbis terrarum a mari Scythico in mare Britannicum. Atque hæ consequentiæ aquarum manifesto volvuntur ab oriente in occidentem. In quo advertendum inprimis, in istis tantum duobus locis maria esse pervia et integrum circulum conficere posse; cum contra per medios mundi tractus, objectu duplici Veteris et Novi Orbis abscindantur et compellantur (tamquam in ostia fluminum) in duos illos alveos oceanorum geminorum Atlantici et Australis, qui oceani exporriguntur inter austrum et septentriones; quod adiaphorum est ad motum consecutionis ab oriente in occidentem. Ut verissime omnino capiatur motus verus aquarum ab istis quas diximus extremitatibus orbis, ubi non impediuntur, sed permeant. Atque primum experimentum hujusmodi est. Secundum autem tale.

Supponatur fluxum maris ad ostium freti Herculei fieri ad boram aliquam certam, constat accedere fluxum ad caput Sancti Vincentii tardius quam ad ostium illud; ad caput finis terræ tardius quam ad caput Sancti Vincentii; ad Insulam Regis tardius quam ad caput finis terræ; ad insulam Hechas tardius quam ad Insulam Regis; ad ingressum canalis Anglici tardius quam ad Hechas; ad littus Normannicum tardius quam ad ingressum canalis. Hucusque ordinatim; ad Gravelingam vero, verso prorsus ordine (idque magno saltu), quasi ad eandem horam cum ostio freti Herculei. Hoc experimentum secundum ad experimentum primo trahimus. Existimamus enim, (quemadmodum jam dictum est) in mari Indico et in mari Scythico veros esse cursus aquarum, ab oriente scilicet in occidentem, pervios et integros; at in alveis maris Atlantici atque Australis compulsos, et transversos, et refractos ab objectu terrarum, quæ utrinque in longum ab Austro ad Boream exporriguntur, et nusquam, nisi versus extremitates, liberum dant exitum aquis. Verum compulsio illa aquarum, quæ causatur a mari Indico versus Boream, et in opposito a mari Scythico versus Austrum, spatiis immensum differunt ob differentem vim et copias aquarum. Universus igitur oceanus Atlanticus usque ad mare Britannicum cedit impulsioni maris Indici; at superior tantum Atlantici maris pars, nimirum ea quæ jacet versus Daniam et Norvegiam, cedit impulsiom maris Scythici. Hoc vero ita fieri necesse est. Etenim duæ magnæ insulæ Veteris Orbis et Novi Orbis eam sunt sortitæ figuram, atque ita exporriguntur, ut ad Septentriones latæ, ad Austrum acutæ sint. Maria igitur contra ad Austrum magna occupant spatia, ad Septentriones vero (ad dorsum Europæ et Asiæ atque Americæ) parva. Itaque ingens illa moles aquarum quæ venit ab oceano Indico, et reflectit in mare Atlanticum, potis est compellere et trudere 
encontram-se manifestos desde o oceano Índico até o oceano Atlântico, e ele é mais rápido e mais forte em direção ao estreito de Magalhães, onde se encontra a saída para o ocidente; grande, do mesmo modo, na parte oposta do orbe das terras do mar Scytico para o mar Britânico. Essas sucessões das águas giram evidentemente de oriente para ocidente. No que se deve primeiramente advertir que somente nesses dois lugares os mares são acessíveis e podem completar um círculo inteiro; quando, ao contrário, nas regiões centrais do mundo pelo duplo obstáculo do Velho e Novo Mundo, separam-se e são compelidos (como na foz dos rios) para aqueles dois leitos profundos dos oceanos gêmeos Atlântico e Austral, oceanos que se estendem de austral para setentrião; ${ }^{6}$ o que é indiferente para o movimento de progressão de oriente para ocidente. De modo que verdadeiramente se apreende o movimento verdadeiro das águas a partir daquelas que chamamos as extremidades da Terra, onde não são impedidos, mas chegam ao fim. Deste modo é o primeiro experimento. O segundo, entretanto, é como se verá a seguir.

Suponha-se que o fluxo do mar na embocadura do estreito de Hércules ocorra numa determinada hora exata; fica evidente que o fluxo se aproxima ao cabo de São Vicente mais lentamente do que àquela embocadura; ao cabo do Fim da Terra mais lentamente do que ao cabo de São Vicente; à Ilha do Rei mais lentamente do que ao cabo do Fim da Terra; à ilha Hechas mais lentamente do que à Ilha do Rei, à embocadura do canal Inglês mais lentamente do que a Hechas; ao litoral da Normandia mais lentamente do que à embocadura do canal. Até esse ponto ordenadamente, à Gravelinga, porém, na ordem diretamente inversa (com um grande salto), quase que à mesma hora que à embocadura do estreito de Hércules. Aproximemos este segundo experimento do primeiro, pois estimamos (como já foi dito) que no mar Índico e no mar Scytico os verdadeiros cursos das águas correm diretamente de oriente para ocidente, acessíveis e íntegros; e nas cavidades profundas do mar Atlântico e Austral [são] forçados, desviados e refratados pelo obstáculo das terras, que se estendem longitudinalmente de austral a boreal e nunca, a não ser nas extremidades, dão livre saída às águas. Contudo, essas águas acumuladas, que são causadas do mar Índico para boreal e, ao contrário, do mar Scytico para austral, diferem imensamente pelos espaços por causa da força diferente e da grande quantidade de águas. Portanto, todo o oceano Atlântico até o mar Britânico cede ao impulso do mar Índico; e apenas a parte superior do mar Atlântico, exatamente aquela que está próxima à Dinamarca e à Noruega, cede ao impulso do mar Scytico. E é necessário que isso ocorra assim. Com efeito, as duas grandes ilhas do Velho e do Novo Mundo configuraram-se casualmente e estenderam-se de tal modo que são amplas para setentrião e estreitas para austral. Portanto, os mares, ao contrário, ocupam grandes espaços para austral, mas pequenos espaços para setentrião (nas costas da Europa, Ásia e América). E aquela grande quantidade de água que vem do oceano Índico e desvia-se para o mar Atlântico é capaz de compelir e empurrar 
cursum aquarum continua successione quasi ad mare Britannicum, quæ successio est versus Boream. At illa longe minor portio aquarum, quæ venit a mari Scythico, quæque etiam liberum fere habet exitum in cursu suo proprio versus occidentem ad dorsum Americæ, non potis est cursum aquarum compellere versus Austrum, nisi ad eam quam diximus metam, nempe circa fretum Britannicum. Necesse est autem ut in motibus istis oppositis sit tandem aliqua meta, ubi occurrant et conflictentur, atque ubi in proximo mutetur subito ordo accessionis; quemadmodum circa Gravelingam fieri diximus, limite videlicet accessionis Indicæ et Scythicæ. Atque inveniri Euripum quendam ex contrariis fluxibus circa Hollandiam, non solum ex ea (quam diximus) inversione ordinis horarum in fluxu, sed etiam peculiari et visibili experimento a plurimis observatum est. Quod si hæc ita fiant, reditur ad id, ut necesse sit fieri, ut quo partes Atlantici et littora magis extenduntur ad Austrum et appropinquant mari Indico, eo magis fluxus antevertat in præcedentia, utpote qui oriatur a motu illo vero in mari Indico; quo vero magis ad Boream (usque ad limitem communem, ubi repelluntur a gurgite antistropho maris Scythici) eo tardius atque in subsequentia. Id vero ita fieri, experimentum istud progressus a freto Herculeo ad fretum Britannicum, plane demonstrat. Itaque arbitramur etiam fluxum circa littora Africæ antevertere fluxum circa fretum Herculeum, et verso ordine fluxum circa Norvegiam antevertere fluxum circa Suediam; sed id nobis experimento aut historia compertum non est.

Tertium experimentum est tale: Maria clausa ex altera parte, quæ Sinus vocamus, si exporrigantur inclinatione aliqua ab oriente in occidentem, quæ in consequentia est cum motu vero aquarum, habent fluxus vigentes et fortes; si vero inclinatione adversa, languidos et obscuros. Nam et mare Erythræum habet fluxum bene magnum, et Sinus Persicus, magis recta petens occidentem, adhuc majorem. At mare Mediterraneum, quod est sinuum maximus, et hujus partes Tyrrhenum, Pontus et Propontis, et similiter mare Balticum, quæ omnia reflectunt ad orientem, destituuntur fere, et fluxus habent imbecillos. At ista differentia maxime elucescit in partibus Mediterranei, quæ quamdiu vergunt ad orientem, aut flectunt ad septentriones (ut in Tyrrheno et in iis, quæ diximus, maribus) quiete agunt absque æstu multo. At postquam se converterint ad occidentem, quod fit in mari Adriatico, insignem recuperant fluxum. Cui accedit et illud, quod in Mediterraneo refluxus ille tenuis (qualis invenitur) incipit ab oceano, fluxus a contraria parte, ut aqua magis sequatur cursum ab oriente quam refusionem oceani. Atque his tantum tribus experimentis in præsentia utemur ad inquisitionem illam secundam. 
o curso das águas em contínua sucessão até as proximidades do mar Britânico, sucessão que vai em direção ao boreal. Mas aquela muito menor porção das águas que vem do mar Scytico, as quais têm praticamente a saída livre no seu próprio curso em direção ao ocidente para as costas da América, não é capaz de compelir o curso das águas em direção ao austral, a não ser àquela meta de que falamos, certamente próximo do estreito Britânico. É necessário, porém, que nesses movimentos opostos exista finalmente alguma meta, onde ocorram e agitem-se e onde, na proximidade, subitamente se mude a ordem de acesso, como dissemos ocorrer próximo a Gravelinga, isto é, o limite do Índico e do Scytico. Muitos observaram que uma certa corrente violenta se forma causada pelos fluxos próximos da Holanda, não apenas em virtude (do que chamamos) inversão da ordem das horas no fluxo, mas também por experimento particular e visível. Porque, se essas coisas são assim, voltamos ao seguinte, que é necessário ocorrer que, onde as partes do Atlântico e os litorais mais se estendem para austral e se aproximam do mar Índico, aí mais o fluxo se antecipa, como aquele que nasce do movimento verdadeiro do mar Índico; mas onde [se estende] mais para boreal (até o limite comum, onde se afastam da corrente contrária do mar Scytico), ali mais se retarda e subseqüentemente. Mas este experimento do avanço do estreito de Hércules ao estreito Britânico demonstra claramente que isso ocorre assim. Portanto, consideramos que também o fluxo nas costas da África antecipa-se ao fluxo em torno do estreito de Hércules e, alterada a ordem, que o fluxo na Noruega antecipa o fluxo da Suécia, mas isso não conhecemos nem por experimento nem por relato.

O terceiro experimento é o seguinte: os mares fechados de um dos lados, que chamamos golfos, se se estendem por certa inclinação de oriente para ocidente, a qual está na mesma direção que o verdadeiro movimento das águas, possuem fluxos vigorosos e fortes; mas se se estendem na direção oposta, possuem fluxos lânguidos e imperceptíveis. Com efeito, o mar da Eritréia possui um fluxo bem grande, assim como o Golfo Pérsico, que está mais diretamente dirigido para o ocidente, possui um fluxo ainda maior. O mar Mediterrâneo, o maior dos golfos, e cujas partes são o Tirreno, o Ponto e a Propóntide, ${ }^{8}$ e similarmente o mar Báltico, os quais estão todos voltados para o oriente, quase estão privados da maré e possuem fluxos fracos. E essa diferença se evidencia, principalmente, nas partes do Mediterrâneo que se voltam por algum tempo para o oriente ou se inclinam para setentrião (como no Tirreno e naqueles mares dos quais falamos), seguem tranqüilamente sem muita maré. Depois de voltaremse para o ocidente, o que ocorre no mar Adriático, recuperam um fluxo notável; e a isso acrescenta-se que, no Mediterrâneo, aquele tênue refluxo (tal qual é encontrado) começa do oceano, e o fluxo começa do lado oposto, de modo que a água segue mais o curso a partir do oriente do que o refluxo do oceano. Utilizemos agora apenas esses três experimentos para a segunda investigação. 
Possit tamen adjici probatio quædam consentanea cum his quæ dicta sunt, sed abstrusioris cujusdam naturæ; ea est, ut petatur argumentuim hujusce motus ab oriente in occidentem, quem aquis adstruximus, non solum a consensu cœli (de quo jam dictum est) ubi iste motus in flore est ac fortitudine præcipua, sed etiam a terra, ubi protinus videtur cessare; ita ut ista inclinatio sive motus vere sit cosmicus, atque omnia a fastigiis coeli usque ad interiora Terræ transverberet. Intelligimus enim conversionem istam ab oriente in occidentem fieri scilicet (quemadmodum revera invenitur) super polos australem et borealem. Verissime autem diligentia Gilberti nobis hoc reperit; omnem terram et naturam (quam appellamus terrestrem) non delinitam sed rigidam, et, ut ipse loquitur, robustam, habere directionem sive verticitatem latentem, sed tamen per plurima exquisita experimenta se prodentem, versus Austrum et Boream. Atque hanc tamen observationem plane minuimus, atque ita corrigimus, ut hoc asseratur tantum de exterioribus concretionibus circa superficiem terræ, et minime producatur ad viscera ipsius terræ (nam quod Terra sit magnes interim levi omnino phantasia arreptum est; fieri enim prorsus nequit, ut interiora Terræ similia sint alicui substantiæ, quam oculus humanus videt, siquidem omnia apud nos a sole et cœlestibus laxata, subacta, aut infracta sint, ut cum iis quæ talem nacta sunt locum, quo vis cœlestium non penetret, neutiquam consentire possint) sed quod nunc agitur, superiores incrustationes sive concretiones terræ videntur consentire cum conversionibus cœli, aëris, atque aquarum, quatenus consistentia et determinata cum liquidis et fluidis consentire queant, hoc est, non ut volvantur super polos, sed dirigantur et vertantur versus polos. Cum enim in omni orbe volubili, qui vertitur super polos certos, neque habet motum centri, sit participatio quædam naturæ mobilis et fixæ; postquam per naturam consistentem sive se determinantem, ligatur virtus volvendi; tamen manet et intenditur, et unitur virtus illa et appetitus dirigendi se; ut directio et verticitas ad polos in rigidis, sit eadem res cum volubilitate super polos in fluidis.

Superest inquisitio tertia: unde et quomodo fiat reciprocatio illa sexhoraria astuum, quæ incidit in quadrantem motus diurni cum differentia quam diximus? Id ut intelligatur, snpponatur orbem terrarum universum aqua cooperiri, ut in diluvio generali. Existimamus aquas, quippe ut in orbe integro, neque impedito, semper in progressu se commoturas ab oriente in occidentem singulis diebus ad certum aliquod spatium (idque profecto non magnum ob exsohitionem et enervationem virium hujus motus in confiniis terræ) cum ex nulla parte objectu terræ impediantur aquæ aut cohibeantur. 
Poderia, contudo, ser acrescentada uma certa prova em conformidade com o que foi dito, mas de uma natureza mais difícil; e ela procede, como requer o argumento desse movimento de oriente para ocidente, o qual atribuímos às águas, não só a partir do consenso do céu (do que já falamos), onde esse movimento está no vigor e na potência máxima, mas também a partir da Terra, onde imediatamente parece cessar, de tal modo que essa inclinação ou movimento seja verdadeiramente cósmico e a todos penetre desde as partes mais altas do céu até as mais interiores da Terra. De fato, pensamos que essa conversão de oriente para ocidente ocorre evidentemente (como de fato se constata) sobre os pólos austral e boreal. Muito verdadeiramente, porém, o trabalho de Gilbert ${ }^{9}$ nos mostrou que toda a Terra e a natureza (que chamamos terrestre) não abrandada, mas rígida e, como ele próprio afirma, robusta, tem a direção ou a vertigem latente, mostrando-se, contudo, por vários experimentos selecionados, na direção austral e boreal. Contudo, atenuamos totalmente essa observação, e a corrigimos, de modo que isso se afirme apenas das concreções externas na superfície da Terra, e absolutamente não penetre nas entranhas da própria Terra (com efeito, que a Terra seja, entrementes, um magneto é produzido por uma fantasia precipitada, pois é impossível ocorrer que as partes mais interiores da Terra sejam semelhantes a alguma substância que o olho humano vê, desde que tudo que está ao nosso alcance se expande e se beneficia ou desgasta pelo Sol e pelos céus, de forma que de nenhum modo possam estar de acordo com aquelas coisas que se localizam onde a força dos céus não penetra); mas trata-se agora de que os revestimentos superiores ou as concreções da Terra parecem concordar com as conversões do céu, do ar e das águas, até onde coisas sólidas e delimitadas podem agir em consenso com os líquidos e os fluidos, isto é, de modo que não retornem sobre os pólos, mas dirijam-se e vertam em direção aos pólos. Pois, visto que em todo globo que gira, e gira sobre pólos fixos e não tem um movimento do centro, há uma certa participação de uma natureza móvel e fixa; uma vez que a capacidade de girar está associada a uma natureza consistente e que se determina a si mesma, no entanto, essa capacidade e inclinação de direcionar-se a si mesma permanece, é intensificada e concentrada, de modo que a direção e a verticidade para os pólos nos corpos rígidos seja a mesma coisa que a rotação sobre os pólos nos fluidos.

Falta a terceira investigação: de onde e como se faz a reciprocação de seis horas das marés, que coincide com o quadrante do movimento diurno, com a diferença que apontamos? Para entender isso, suponha-se que a totalidade do globo terrestre se recobrisse completamente de água, como no dilúvio universal. Estimamos que as águas, recobrindo a totalidade do globo, sem haver impedimento, sempre avançando pôr-se-ão em movimento de oriente para ocidente, todos os dias, numa certa distância (e esta certamente não grande, pela dissolução e enfraquecimento das forças desse movimento nos confins da Terra), visto que as águas não serão impedidas nem retidas de nenhuma parte 
Supponatur rursus, Terram unicam insulam esse, eamque in longitudine exporrigi inter austrum et septentriones, quæ forma ac situs motum ab orionte in occidentem maxime frenat et obstruit. Existimamus aquas cursum suum directum et naturalem ad tempus perrecturas, sed rursus ab insula illa repercussas paribus intervallis relapsuras; itaque unicum tantum fluxum maris in die futurum fuisse, et unicum similiter refluxum, atque horum singulis circiter 12 horas attributum iri. Atque ponatur jam (quod verum est et factum ipsum) terram in duas insulas divisam esse, Veteris scilicet et Novi Orbis (nam terra australis situ suo rem istam non magnopere disturbat, quemadmodum nec Groenlandia aut Nova-zembla), easque ambas insulas per tres fere mundi zonas exporrigi, inter quas duo oceani, Atlanticus et Australis, interfluunt, et ipsi nunquam nisi versus polos pervii; existimamus necessario sequi, ut duo isti obices naturam duplicis reciprocationis universæ moli aquarum insinuent et communicent, et fiat quadrans ille motus diurni; ut aquis scilicet utrimque frænatis, fluxus et refluxus maris bis in die per spatia scilicet sex horarum se explicet, cum duplex fiat processio, et duplex itidem repercussio. Illæ vero duæ insulæ si instar cylindrorum aut columnarum, per aquas exporrigerentur æquis dimensionibus et rectis littoribus, facile demonstraretur, et cuivis occurreret iste motus, qui jam tanta varietate posituræ terræ et maris confundi videtur et obscurari. Neque etiam est difficile conjecturam capere nonnullam, qualem isti motui aquarum incitationem tribuere consentaneum sit, et quanta spatia in uno die conficere possit. Si enim sumantur (in æstimationem hujus rei) littora aliqua ex iis quæ minus montosa aut depressa sunt et oceano libero adjacent, et capiatur mensura spatii terræ inter metam fluxus et metam refluxus, interjacentis, atque illud spatium quadruplicetur propter æstus singulis diebus quaternos, atque is numerus rursus duplicetur propter æstus ad adversa littora ejusdem oceani, atque huic numero nonnihil in cumulum adjiciatur, propter omnium littorum altitudinem, quæ ab ipsa fossa mari semper aliquantum insurgunt; ista computatio illud spatium productura est, quod globus aquæ uno die, si liber ab impedimento esset, ac in orbe circa terram semper in progressu moveret, conficere possit; quod certe nil magnum est. De differentia autem illa quæ coincidit in rationes motus Lunæ, et efficit periodum menstruam; id fieri existimamus, quod spatium sexhorarium non sit mensura exacta reciprocationis, quemadmodum nec motus diurnus alicujus planetarum restituitur exacte in horis 24, minime autem omnium Luna. Itaque mensura fluxus et refluxus non est quadrans motus stellarum fixarum, qui est 24 horarum, sed quadrans diurni motus Lunæ. 
por um obstáculo de terra. Suponha-se, de outro modo, concentrar-se a terra em uma única ilha que se estendesse longitudinalmente entre austral e setentrião, e cuja forma e lugar [que ocupa] freia e obstrui maximamente o movimento de oriente para ocidente; consideremos que as águas continuarão momentâneamente seu curso natural e retilíneo, ma retornarão refluindo em sentido oposto daquela ilha a intervalos iguais; portanto, apenas um único fluxo diário ocorrerá e similarmente um único refluxo repartidos cada um deles em cerca de 12 horas. Suponha-se agora (o que é verdadeiro e é o próprio fato) que a terra está dividida em duas ilhas, ou seja, no Velho e no Novo Mundo (com efeito, a Terra Austral, por sua localização, faz pouca diferença, como tampouco a Groelândia e a Nova Zelândia), e que ambas as ilhas se estendem por quase três regiões do mundo, entre as quais fluem dois oceanos, o Atlântico e o Austral, que somente têm passagem em direção aos pólos; estimamos seguir-se necessariamente que esses dois obstáculos insinuem e comuniquem a natureza da dupla reciprocação universal pela imensa mole de água e se produza no quadrante do movimento diurno, de modo que, como as águas são evidentemente refreadas de ambos os lados, o fluxo e o refluxo do mar espalha-se duas vezes ao dia, certamente em períodos de 6 horas, já que duplo é o avanço e, do mesmo modo, dupla a repercussão. Com efeito, essas duas ilhas, se se estendessem à semelhança de cilindros ou de colunas pelas águas em dimensões iguais e com litorais regulares, demonstrar-se-ia facilmente esse movimento, que agora parece com tanta variedade de disposição de terra e de mar confundir-se e obscurecer-se, e a partir de onde ele ocorreria. E não é difícil conjecturar qual rapidez é coerente atribuir a este movimento das águas, e quanto espaço ele poderia perfazer em um único dia. Com efeito, se forem tomados (na avaliação disso) alguns litorais desses que são menos montanhosos ou com menor declive e estão próximos de mar aberto, e se tomar a medida do espaço de terra que intermedeia o limite do fluxo e o limite do refluxo, e seja esse espaço quadruplicado por causa das marés quaternárias de cada dia, e esse número seja, por sua vez, duplicado em virtude das marés nos litorais opostos de cada oceano, e a esse número seja acrescentado algo em excesso, por causa da altitude de todos os litorais, que sempre se elevam em alguma extensão a partir da própria profundeza do mar, este cálculo produzirá aquela distância que o globo de água poderia perfazer em um dia, se estivesse livre de obstáculo e sempre se movesse progressivamente em círculo ao redor da Terra, a qual seguramente não é nada grande. Por outro lado, sobre aquela diferença que coincide com as proporções do movimento da Lua e produz um período mensal, julgamos ocorrer que o intervalo de 6 horas não é a medida exata da reciprocação, do mesmo modo que também o movimento diurno dos planetas não se restitui exatamente em 24, horas, e isto vale sobretudo para a Lua. Portanto, a medida do fluxo e refluxo não é a quarta parte do movimento das estrelas fixas, que é de 24, horas, mas a quarta parte do movimento diurno da Lua. 


\section{MANDATA}

Inquiratur utrum hora fluxus circum littora Africæ antevertat horam fluxus circa fretum Herculeum? Inquiratur utrum hora fluxus circa Norvegiam antevertat horam fluxus circa Suediam, et illa similiter horam fluxus circa Gravelingam?

Inquiratur utrum hora fluxus ad littora Brasiliæ antevertat horam fluxus ad littora Hispaniæ Novæ et Floridæ?

Inquiratur utrum hora fluxus ad littora Chinæ non inveniatur ad vel prope horam fluxus ad littora Peruviæ, et ad vel prope horam refluxus ad littora Africæ et Floridæ?

Inquiratur quomodo hora fluxus ad littora Peruviana discrepet ab hora fluxus circa littora Hispaniæ Novæ, et particulariter quomodo se habeant differentiæ horarum fluxuum ad utraque littora Isthmi in America; et rursus quomodo hora fluxus ad littora Peruviana respondeat horæ fluxus circa littora Chinæ?

Inquiratur de magnitudinibus fluxuum ad diversa littora non solum de temporibus sive horis. Licet enim causentur fere magnitudines fluxuum per depressiones littorum, tamen nihilominus communicant etiam cum ratione motus veri maris, prout secundus est aut adversus.

Inquiratur de mari Caspio (quæ sunt bene magnæ portiones aquarum conclusæ, absque ullo exitu in oceanum) si patiantur fluxum et refluxum, vel qualem; siquidem nostra fert conjectura aquas in Caspio posse habere fluxum unicum in die, non geminatum, atque talem ut littora orientalia ejusdem maris deserantur, cum occidentalia alluantur.

Inquiratur utrum fluxus augmenta in noviluniis et pleniluniis, atque etiam in æquinoxiis, fiant simul in diversis mundi partibus? Cum autem dicimus simul intelligimus non eadem hora, (variantur enim hor secundum progressus aquarum ad littora, ut diximus), sed eodem die.

\section{More}

Non producitur inquisitio ad explicationem plenam consensus motus menstrui in mari cum motu Lunæ; sive illud fiat per subordinationem, sive per concausam. 


\section{INVESTIGAÇÕES ${ }^{10}$}

Investigue-se: a hora do fluxo nas proximidades das costas da África precede a hora do fluxo próximo ao estreito de Hércules? Investigue-se: a hora do fluxo próximo da Noruega precede à hora do fluxo perto da Suécia e esta, do mesmo modo, precede à hora do fluxo nas proximidades da Groelândia?

Investigue-se: a hora do fluxo na costa do Brasil precede à hora do fluxo na costa da Nova Espanha e da Flórida?

Investigue-se: a hora do fluxo no litoral da China não se encontraria na mesma ou quase na mesma hora do fluxo no litoral do Peru, na mesma ou quase na mesma hora do refluxo nas costas da África e da Flórida?

Investigue-se: de que modo a hora do fluxo nas costas peruanas difere da hora do fluxo nas proximidades do litoral da Nova Espanha e, particularmente, de que modo se dão as diferenças dos horários dos fluxos em ambas as costas do Istmo na América; e inversamente de que modo a hora do fluxo nas costas peruanas corresponde à hora do fluxo nas proximidades das costas da China?

Investigue-se acerca das magnitudes dos fluxos nos diferentes litorais, não somente acerca dos períodos mas das horas, pois, embora geralmente as magnitudes dos fluxos sejam causadas pelas inclinações dos litorais, contudo comunicam-se também com a razão do movimento verdadeiro do mar, segundo esteja no mesmo sentido ou no sentido oposto.

Investigue-se acerca do mar Cáspio (que contém imensas quantidades de águas enclausuradas, sem nenhuma saída para o oceano), se suas águas sofrem o fluxo e refluxo, ou algo semelhante; se realmente se sustenta nossa conjectura de que as águas no Cáspio possam ter um único fluxo ao dia, não duplo, tal que os litorais orientais desse mar se esvaziam, quando os ocidentais se inundam.

Investigue-se: os aumentos do fluxo nos novilúnios e plenilúnios, e também nos equinócios, ocorrem simultaneamente nas diferentes partes do mundo? Quando, porém, dizemos simultaneamente, entendemos não na mesma hora (pois as horas, como dissemos, variam segundo a progressão das águas nos litorais), mas no mesmo dia.

\section{RESTRIÇÕES}

A investigação não alcança a explicação plena do consenso do movimento mensal no mar com o movimento da Lua; que isso se faça por subordinação, ou por causa concomitante. 


\section{ZYZYGIA}

Inquisitio præsens conjungitur cum inquisitione Utrum terra moveatur motu diurno? Si enim æstus maris sit tamquam extrema diminutio motus diurni; sequetur globum terræ esse immobilem, aut saltem moveri motu longe tardiore quam ipsas aquas. 
De fluXU ET RefluXu MARis / Do FluXo e REFLUXo do MAR

\section{Conjunções}

A presente investigação está ligada a outra investigação: a Terra se moveria com movimento diurno? Pois se a maré do mar fosse como a máxima diminuição do movimento diurno, seguir-se-ia que o globo terrestre estaria imóvel ou, pelo menos, mover-se-ia com um movimento muito mais lento do que aquele das próprias águas.

Traduzido do original em latim por Adriano Machado Ribeiro e Letizio Mariconda

Revisão técnica de Roberto Bolzani Filho

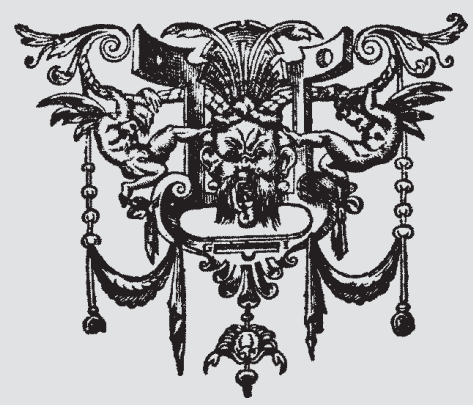




\section{Notas}

1 Foram utilizadas para esta tradução duas impressões do texto latino, aquela que se encontra no volume 3 das obras de Francis Bacon, editadas por Spedding; Ellis e Heath e publicadas em 1876; a segunda é a que se encontra na edição bilingüe (latim/inglês) de Graham Rees, publicada em 1996 dos escritos filosóficos que F. Bacon compôs entre 1611 e 1619, edição da qual foi retirado o texto latino aqui publicado.

2 "De austral para boreal", ou seja, do sul para o norte, ou ainda, em direção ao norte.

3 "Ferinos", para significar que seriam solitários, como as feras que vivem isoladas. A idéia é que mesmo o movimento irregular ou próprio dos planetas não ocorre separadamente mas encontra-se em uma espécie de harmonia consensual com todas as demais coisas do universo. A idéia está evidentemente associada à concepção de natureza de Francis Bacon.

4. "Raptam primis mobilis", literalmente, "o rapto do primeiro móvel” para significar que o primeiro móvel como que arrastaria (com violência) os demais corpos celestes, o que seria obviamente contrário à natureza, entendida por Bacon como consenso cooperativo.

5 O Euro é o vento que sopra do leste e, portanto, do continente para o Atlântico; o Zéfiro sopra de oeste e, portanto, do Atlântico para o continente. No caso, os termos designam os pontos cardeais leste e oeste respectivamente.

6 Isto é, de sul para o norte.

7 "As colunas de Hércules" é a antiga denominação do estreito de Gibraltar.

8 O Ponto é hoje chamado de Dardanelos; trata-se de um longo estreito que separa o sudeste da Europa da Ásia Menor, ligando o mar Egeu ao mar de Mármara. "Propóntide” é a antiga designação do mar de Mármara, um pequeno mar do Mediterrâneo oriental, que separa o sudeste da Europa e a Ásia Menor.

9 Bacon está fazendo referência ao De mundo nostro sublunari philosophia nova (Nova filosofia de nosso mundo sublunar) de William Gilbert, onde é desenvolvida uma teoria da verticidade da Terra, isto é, uma tentativa de explicação de por que a Terra gira sobre pólos fíxos.

100 termo "mandata" (aqui traduzidos como investigações) expressa um procedimento que faz parte da história natural baconiana. Os mandata constituem "esboços de experimentos calculados para completar dados incompletos, esboços que constituem uma história designata ou uma história que está por nascer” (Rees, 1996a,p.xxv, nota 37), portanto, uma história em processo de gestação. Como se vê aqui, trata-se de propostas de investigações que podem conduzir não apenas a completar os dados observacionais, mas acima de tudo são conduzidas no sentido de confirmar ou infirmar a hipótese proposta na investigação, neste caso, a hipótese de Bacon. 